\title{
In memoriam William Golding: escudriñando los rincones oscuros de la naturaleza humana
}

\author{
Claire JOYSMITH \\ Universidad Nacional Autónoma de México
}

\begin{abstract}
La falta de sueño y el exceso de comprensión me vuelven un tanto loco, creo, igual que ocurre con todos los hombres que viven en el mar, demasiado cerca los unos de los otros y demasiado cerca, por ende, de todo lo que hay de monstruoso bajo el sol y la luna. (Edmund Talbot en Ritos de paso)
\end{abstract}

Comunicarnos es nuestra pasión y nuestra desesperanza. (Sammy Mountjoy en Caída libre)

La vida es fundamentalmente injusta. Como novelista no puedo ofrecer una explicación total del universo, pero creo que existe un mundo en el más allá. He intentado siempre ofrecer a través de mis obras una sugerencia cósmica de aproximación al universo. (William Golding en una entrevista realizada en España, en 1992)

Nació el 19 de septiembre de 1911 en Cornualles, Gran Bretaña. Estudió ciencias en Brasenose College, Oxford, pero luego optó por la literatura inglesa. Trabajó como actor durante varios años e ingresó a la Marina Real Británica durante la Segunda Guerra Mundial. Laboró varios años como maestro de primaria y secundaria en la escuela Bishop Wordsworth, en Salsbury. Después de varios fracasos en el campo novelístico, escribió Lord of the Flies (El señor de las moscas) en 1954, novela que fue rechazada por siete editoriales antes de convertirse en best-seller y ser traducida a una veintena de idiomas y que, desde hace más de dos décadas, se usa como material de lectura en todas las escuelas primarias y secundarias de Gran Bretaña. Desde entonces hasta la fecha de su muerte (1993) se dedicó de tiempo completo al oficio de escritor y a velear en sus ratos libres. 
Principales premios y reconocimientos: premio británico Booker McConnel (1980), Caballero de la Corona Británica (1982), Premio Nobel (1983), doctor honoris causa por la Universidad de Oviedo en España (1992).

Escribir sobre William Golding con motivo de su muerte me resulta un tanto ambiguo - lo cual no fue el caso cuando hablé acerca de él en el merecido homenaje que se le rindió en la Facultad de Filosofía y Letras en 1991, al celebrarse su octogésimo aniversario. La razón es de hecho muy sencilla: la lectura de su obra dejó en mí como legado huellas de difícil reconciliación.

El primer encuentro con la obra goldingeana ocurrió a mis catorce años, cuando mi padre me sugirió que leyera Lord of the Flies. La intensidad de esa primera lectura fue, pese a las circunstancias individualizadas que tenga esa experiencia, una que creo compartir con miles de lectores.

Ese primer contacto íntimo, altamente emotivo, halló su secuela y contraparte en la lectura que hice durante mis años universitarios, durảnte la licenciatura y el posgrado, pues entonces imperaba la necesidad de racionalizar, etiquetar, encontrar estructuras y patrones. Me descubrí entre los laberintos sinuosos, sorpresivos, engañosos de la narrativa goldingeana, la cual plantea abiertamente un reto al lector. Me resultó impactante la fuerte carga emotiva siempre contenida en una estructura formal impecable, deliberada, en la cual Golding jamás aparta el dedo del renglón de la innovación y cuyas cualidades subversivas se escabullen entre líneas.

Cuando, por azares de la vida, conocí a Golding y tuve la oportunidad de entrevistarlo en diciembre de 1990 (fecha en que honró a la Facultad de Filosofía y Letras con su presencia), las armas académicas de las que hasta entonces me había valido para acercarme a su obra se trastocaron en flechas un tanto prehistóricas y sin blanco: no es casualidad que él se haya definido a sí mismo como "un blanco móvil".

Así fue que mi andamiaje crítico se vino abajo. Con la poderosa presencia de este hombre (su apariencia fue descrita como "artúrica" por un crítico) y su apabullante sencillez, logré recobrar, de manera un tanto escurridiza, el impacto inicial de sus textos. Cualquier ilusión de abordar la obra goldingeana como lo había hecho terminó de tajo, obligándome a iniciar una búsqueda que se aproximara a una visión más integral, 
que abarcara esa emotividad destilada de su obra, en donde queda desglosada una visión cristalina y, de manera paradójica, extraordinariamente compleja, turbia e inquietante, del ser humano.

Golding es un genio de la narrativa que está comprometido con el escudriñamiento de los rincones más recónditos y oscuros del alma; que se regodea en someter al ego humano a un escrutinio intenso y despiadado, labor nacida de una compasión desmedida por la condición humana. Acentúa los rasgos divinos de lo humano y subraya lo bajo que éste ha caído. Jamás muestra reparos ante su compromiso de señalar las grandes fallas del ser humano, sin excluirse a sí mismo, y ofrecerle un espacio para la posible redención propia. Por ello tal vez no sorprende que Golding se haya proclamado, en los albores de su carrera de escritor, como "un pesimista universal, pero un optimista cósmico".

Golding plantea las preguntas más dificiles acerca del ser humano para luego intentar con humildad buscar algo que pueda servir de respuesta. Aparenta llevar de la mano al lector, a la vez esmerándose en mostrarle la facilidad con que éste se deja engañar - ante todo por si mismo. Esto queda ampliamente ilustrado en sus clásicos "finales sorpresa", los cuales tienen la función, entre varias otras, de violentar al lector, de obligarlo a reaccionar, a hacerse preguntas sin respuesta fácil 0 , incluso, sin respuesta alguna.

Golding busca con insistente urgencia cuestionar y cimbrar las raíces mismas de una conformidad que, a sus ojos, amenaza con debilitar aún más al ser humano contemporáneo y a su sociedad. El lector, arrasado emocionalmente, opta, a pesar de sí, por la entrega total o el rechazo irrevocable: no se le permite impavidez alguna en su lectura.

De hecho, el reconocimiento dado a Golding siempre se ha caracterizado, considerando el enorme alcance de su obra, por un margen de reserva, una especie de pudor muy singular. Aun -0 mejor dicho, sobre todo- en Inglaterra, su país natal, la crítica se ha mostrado en ocasiones mordaz. $Y$ es que Golding plantea ciertas verdades incómodas, una visión nada halagadora del ser humano "civilizado"; como él mismo ofreció a modo de explicación: "la verdad nunca está de moda".

Sin duda la escasez de tesis sobre Golding, por ejemplo, en las universidades inglesas ( $\mathrm{y}$ hablo de hace apenas tres años), nos dice más acerca de un temor a abordar la intensidad sui generis de su obra que de su fama de escritor "oscuro" o de sus variadas e intrincadas estrategias narrativas.

La temática de la obra goldingeana se centra, ante todo, en la capacidad innata y desmedida del ser humano para hacer el mal, y su 
incapacidad para convivir con otros, a pesar de ser por naturaleza un ente social. También destaca la preocupación por la trágica renuencia del ser humano a verse tal y como es, con lo cual se va abriendo o cerrando, según el caso, la brecha entre lo que logra descubrir y lo que es capaz de aceptar acerca de si mismo.

Comprometido sin tregua con su oficio como escritor, Golding aborda también la temática de esa inmensa distancia entre lo que se busca comunicar, que se desprende de la experiencia personal, y lo que permanece incomunicable e incomunicado. Es así como el mismo hecho de escribir y de regodearse con pícara sonrisa en lo subversivo podría colocarlo bajo el rubro autocreado de "optimista cósmico".

Mas el papel de escritor que asume Golding dista mucho de aquel otro de mitificado "visionario de mirada perdida", pues, según dice él mismo, su trabajo se acerca más a un oficio "artesanal", papel modesto que se asigna a sí mismo en tanto artífice que ejerce control sobre su texto.

Control que se trasluce en la creación ad hoc, en cada uno de sus textos, de ciertas extrategias narrativas que concuerdan con un espacio geográfico e histórico específico. Es a partir de una isla, una roca, un buque, etcétera, que construye un mundo diegético que rebasa las fronteras de una realidad descrita con cuidadoso detalle, para así abrir un abanico de posibles descodificaciones metonímicas, metafóricas y simbólicas.

La trayectoria de la obra goldingeana, la cual abarca treinta y cinco años (1954-1989), se caracteriza por una constante transición en la que pueden distinguirse tres bloques. El primero, el más destacado para la crítica y en el cual se muestra una prolífera imaginación narrativa, se inicia con Lord of the Flies (El señor de las moscas, 1954), continúa con The Inheritors (Los herederos, 1955), Pincher Martin (Martín el náufrago, 1956), Free Fall (Caida libre, 1959) y culmina diez años más tarde con la novela de mayor complejidad y punto cumbre de la obra goldingeana, The Spire (La construcción de la torre, también traducida como La aguja, 1964).

En el segundo bloque pueden ubicarse aquellas obras menos conspicuas a la mira pública y académica, como los cuentos de The Pyramid ( La pirámide, 1967), The Scorpion God (El dios escorpión, 1971) y Darkness Visible (La oscuridad visible, 1979), novela que se aleja, por desafortunada, del resto de su obra. Aqui también cabría incluir su novela -muy mal recibida por la crítica, por cierto- que funge de catarsis seudoautobiográfica, The Paper Men (Los hombres de papel, 1984), un agresivo desafio a la parafernalia crítico-académica que, según Golding, 
acaba por darle muerte al autor. En este bloque también tiene cabida una variedad de escritos, como una obra de teatro, The Brass Butterfly (La mariposa de latón, 1958), dos volúmenes de ensayo, The Hot Gates (Las puertas ardientes, 1966), A Moving Target (Un blanco móvil, 1982), un poemario (que escribió recién egresado de Oxford, y que él prefirió mantener en el olvido) de 1934, varias obras radiofónicas (Envoy Extraordinary, 1956; Break My Heart, 1961; y Miss Pulkinhorn, 1960), un libro de viajes, An Egyptian Journey (Un viaje egipcio, 1985), todos ellos de menor consecuencia.

Un tercer bloque lo constituye la llamada Sea Trilogy (La trilogia del mar), aunque, según confesó el mismo Golding, él no tenía intenciones de crear una trilogía cuando escribió el primer tomo, Rites of Passage (Ritos de paso, 1980), al cual siguieron Close Quarters (Cuerpo a cuerpo, 1987) y Fire Down Below (Fuego en las entrañas, 1989). En estos tres volúmenes se evoca un mundo dieciochesco a bordo de un decrépito buque rumbo a Australia, narrado en forma epistolar por Edmund Talbot, un pedante aunque simpático aristócrata, cuyo molde estilistico se encuentra en las novelas inglesas del siglo XVIII. Es sobre todo en los dos últimos volúmenes donde aparece, para sorpresa de todo lector que ha seguido de cerca la demás obra goldingeana, una fuerte e inesperada carga cómica, aunque de algún modo latente en algunas obras anteriores, que hace mayor justicia a ese "optimismo cósmico" que menciona Golding.

Resulta claro que, como ha sucedido en el caso de muchos otros escritores, la capacidad de tolerancia de Golding fue en aumento en los últimos años de su vida. Para este autor es cuestión de un giro en su enfoque; como explicó al entrevistársele en México: "me estoy volviendo cada vez menos dogmático, menos interesado en señalar lo que está mal en el universo y más interesado en señalar lo que está ahí".

La obra de William Golding ha dejado huellas indelebles en miles de lectores y, sin duda alguna, lo seguirá haciendo después de haber muerto su autor, a mediados del año pasado, a los ochenta y dos años, muerte que cortó de tajo el proyecto autobiográfico que había anunciado.

Así que valgan unas últimas palabras. No tanto como despedida al autor mismo, sino como reiterada bienvenida a una obra que jamás cesará de cimbrar las raíces de la complacencia fácil en aquellos lectores dispuestos a enfrentar el reto multifacético que plantea la lectura de su obra.

Que en paz descanse William Golding. 